\title{
Evolution and Yoga. Hypothesis: From Reptilian to Intuitional Brain
}

\author{
Carlos Munoz ${ }^{1,2}$ \\ ${ }^{1}$ Suddha Dharma Mandalam, Santiago, Chile \\ ${ }^{2}$ University of Chile, Santiago, Chile \\ Email: gdcarlosmunoz@gmail.com
}

How to cite this paper: Munoz, C. (2020). Evolution and Yoga. Hypothesis: From Reptilian to Intuitional Brain. Open Journal of Philosophy, 10, 266-276.

https://doi.org/10.4236/ojpp.2020.102018

Received: April 13, 2020

Accepted: May 19, 2020

Published: May 22, 2020

Copyright $\odot 2020$ by author(s) and Scientific Research Publishing Inc. This work is licensed under the Creative Commons Attribution International License (CC BY 4.0).

http://creativecommons.org/licenses/by/4.0/

\begin{abstract}
It is amply accepted that biological evolution is centered in gradual phenotypic and genetic changes of living populations through the time. The issue of human existence has worried the man since immemorial time. The intriguing concepts of life and consciousness vary according to the discipline of study. While for West Biologists, life is the ability to be born, to grow and to die, for Yogis Life is Consciousness which compenetrates to beings from nature kingdoms. Is human brain still evolving? The studies of neuroscience, based on classical well-known triune brain proposed by Dr Paul MacLean around the year 1960, estimate that in the human brain resides the genealogical tree of the species as a result of the evolution of millions of years starting from the brain structure of the reptiles. This involves the well-known three levels of the reptilian brain (intinction), the limbic brain (emotions) and the neocortex brain (rationality). Like the biological evolution, it is also possible to consider a spiritual evolution through also different kingdoms of nature. The neuroscientists say that modern man has developed only one-third of his brain capacity. According to this background, the main point of this study is to postulate during next millennia the development of improved neocortex II or "intuitional brain" with neural networks prevailing human noble qualities and subtle essential unity among beings. Today neurological studies reveal that network design of interconnected neurons varies with selfish and non-selfish thoughts. Recently Dr Richard Davidson, a well-known and famous American psychiatrist who also practices meditation techniques, has demonstrated that network neurons of human depression are completely different from those in tenderness. He concludes that "goodness is the base of a healthy brain". Suddha Dharma Mandalam (SDM) is a sacred Spiritual Order which pre-eminent philosophical system contains the most vital principles about life and conduct, aimed at achievement of the material and spiritual progress of humanity. Among others, this Order recommends to their disciples cultivate
\end{abstract}


the noble Atmic qualities including goodness, tolerance, welfare, purity and compassion. Experts from different areas including philosophers and biologists propose that if we teach Yoga to children, the world violence would be eliminated in a single generation.

\section{Keywords}

Biological \& Spiritual Evolution, Reptilian \& Intuitional Brains, Homo sapiens, Homo moralis, Homo spiritualis, Conscience \& Conscience

\section{Introduction}

It is amply accepted that biological evolution is centered in gradual phenotypic and genetic changes of living populations through the time. Of course, much has been learned about humanity's evolutionary origins and biological conditions since Darwin's time, not least from the evidence of paleontology, comparative vertebrate biology and genomics. An emerging field known as "anthropogeny" (Varki et al., 2008) seeks to understand the evolutionary origins of humans and their biological and cultural traits. Studies of human evolution, through international colloquiums integrate disciplines like biologists, anthropologists and philosophers of science reflect upon and commemorate the Darwinian Revolution as it relates to human condition at levels ranging from molecular to the phenotypic, to the social and philosophical. For instance, the first published reports of the complete nucleotide sequence of a human genome appeared near the turn of the 21st century (Lander et al., 2001), and the full sequence of a chimpanzee genome was unveiled soon therefore (Sequencing et al., 2005). Overall, humans and chimpanzees proved to be about $99 \%$ identical in nucleotide regions. A human being is not only Homo sapiens (transitory physical body), but also Homo moralis (transitory inferior conscience) and Homo spiritualis (eternal Superior Conscience). Like biological evolution, it is also possible to consider a spiritual evolution through also different kingdoms of nature. The issue of human existence has worried the man since immemorial time. The intriguing concepts of life and consciousness vary according to the discipline of study. For Biologist, life (word written with lowercase letter) is the ability to be born, to grow and to die. From this perspective, life distinguishes the animal, vegetable and bacterial beings from other natural realities. By other hand, consciousness is defined as integral knowledge of itself and its environment; there are different levels of consciousness from the physical to the spiritual planes. Due to neuroscientists point out that modern man has developed only one-third of his braincapacity, it is plausible to glimpse through the time the appearance of an integral human being resulting from biological and spiritual evolution. Both aspects are discussed in the next sections.

Hypothesis: the present study postulates during next millennia the development of an improved neocortex II with neuronal interconnections prevailing 
noble qualities or "intuitional brain" with neural networks prevailing human noble qualities and subtle essential unity among beings.

\section{Biological Evolution}

The transition from $H$ erectus to $H$. sapiens occurred around 400,000 years ago, although this data is not well determined owing to uncertainty as to whether some fossils are erectus or archaic forms of sapiens. H. erectus persisted for some time in Asia, until 250,000 years ago in China and perhaps until 100,000 years ago in Java, and was contemporary with early members of its descendant species, H. sapiens. Fossil remains of Neandertal hominids with brains as large as those of H. sapiens, appeared in Europe earlier than 200,000 years and persisted until 35,000 years ago (Higham et al., 2014). There are mankind two kinds of heredity: the biological and the cultural. Biological inheritance in humans is very much like that in any other sexually reproducing organism; it is based on transmission of genetic information encoded in DNA from one generation to the next by means of the sex cells. Cultural inheritance is based on transmission of information by a teaching-learning process, which is independent of biological parentage. Biological heredity is Mendelian or vertical; it is transmitted from parent to their children, and only inherited traits can be transmitted to the progeny. However, cultural heredity goes beyond Lamarckian heredity because it is horizontal and oblique and not only vertical.

There is no scientific basis to the claim sometimes made that the biological evolution has stopped at least in technologically advanced countries. It is asserted that the progress of medicine, hygiene, and nutrition have largely eliminated death before middle age; that is, most people live beyond reproductive age, after which death is inconsequential for natural selection. That mankind continues to evolve biologically can be shown because conditions for biological evolution persist. These conditions are genetic variability and differential reproduction. There is a wealth of genetic variation in mankind. With the trivial exception of identical twins, developed from a single fertilized egg, no two people who live now, lived in the past, or will live in the future, are likely to be genetically identical. Much of this variation is relevant to natural selection (Ayala, 1986; Richerson et al., 2005). Natural selection is simple differential reproduction of alternative genetic variants. Natural selection will occur in mankind if the carriers of some genotypes are likely to leave more descendants than the carriers of other genotypes. Natural selection consists of two main components: differential mortality and differential fertility; both persist in modern mankind, although the intensity of selection due to postnatal mortality has been somewhat attenuated. Its evolution has provoked attention from all biomedical sciences. Actual brain is the largest and more complex than any other species, whose cerebral cortex has the greatest cognitive and affective functions. The human brain could continue to evolve in size, functions and sensibility.

A human is not only Homo sapiens, but also Homo moralis and Homo spiri- 
tualis. The morality is a human attribute, to which Darwin attached a special significance: "I ... subscribe to the judgement of those writers who maintain that of all the differences between man and the lower animals the moral sense of conscience is by far the most important'. There is a fundamental distinction between the capacity for ethics (i.e., the human capacity for a moral sense) and the expression of moral norms, which can vary from one human society to another. The former is an inevitable byproduct of the biological evolution of high intelligence, which itself arose from selection pressures for other fitness-enhancing capabilities such as bipedalism and tool use. Moral behavior may be defined as the actions of a person who takes into account in a sympathetic way the impact that the actions have on others. Moral behavior is not attributed to animals (surely, not to all animals and not to the same extent as to the humans). Therefore, evolution raises distinctive questions about the origins and tenets of moral behavior. Other distinctive functional features are self-awareness and death awareness; symbolic (creative) language; tool making and technology; complex and extremely variable forms of cooperation and social organization; legal codes and political institutions: science, literature, and art; and ethics and religion (Cela-Conde \& Ayala, 2007).

\section{Spiritual Evolution}

A human being is not only Homo sapiens with transitory physical body and Homo moralis with transitory conscience, but also Homo spiritualis carrying an "Eternal Conscience". The concept is analyzed through the Vedic knowledge and the scientific evidences in next 3 subsections including the life and Consciousness, biopoiesis and neuroscience brain studies and the Aryan philosophy of Suddha Dharma Mandalam.

\section{Life and Consciousness}

In the East philosophy Brahm is referred as the "the Truth transcendent or Supreme shining of Cosmic Consciousness", where Atman represents the evolving individual spirit of a human being to his image, likeness, power and wisdom (Woodhouse, 1978). The famous well-known Bhagavad Geeta-treasure book of esoteric literature exposing yogic art of Brahm-has recently been discussed by some authors (Reigle, 2007; Bagchee \& Adluri, 2016; Munoz et al., 2020). This Divine Essence or Life (word written with capital letter) appears and evolves in both, lower kingdoms of nature (mineral, vegetable, animal, human) as well as in the upper divine kingdoms (angels, archangels, etc.). It might be mentioned that this Life sleeps in the mineral, wakes up in the animal, dreams in the vegetable and makes self-conscious in the human. When life reaches its maximum expression in a body, then it builds another more appropriate top vehicle. Interestingly, the man is the critical point of evolution developing the self-awareness to realize about his existence since he can contact lower kingdoms through 5 classical sense organs and upper divine kingdoms through soul organs like spiritual vision (third Eye/Ajna chakra) and the meditation technique (Figure 1). 


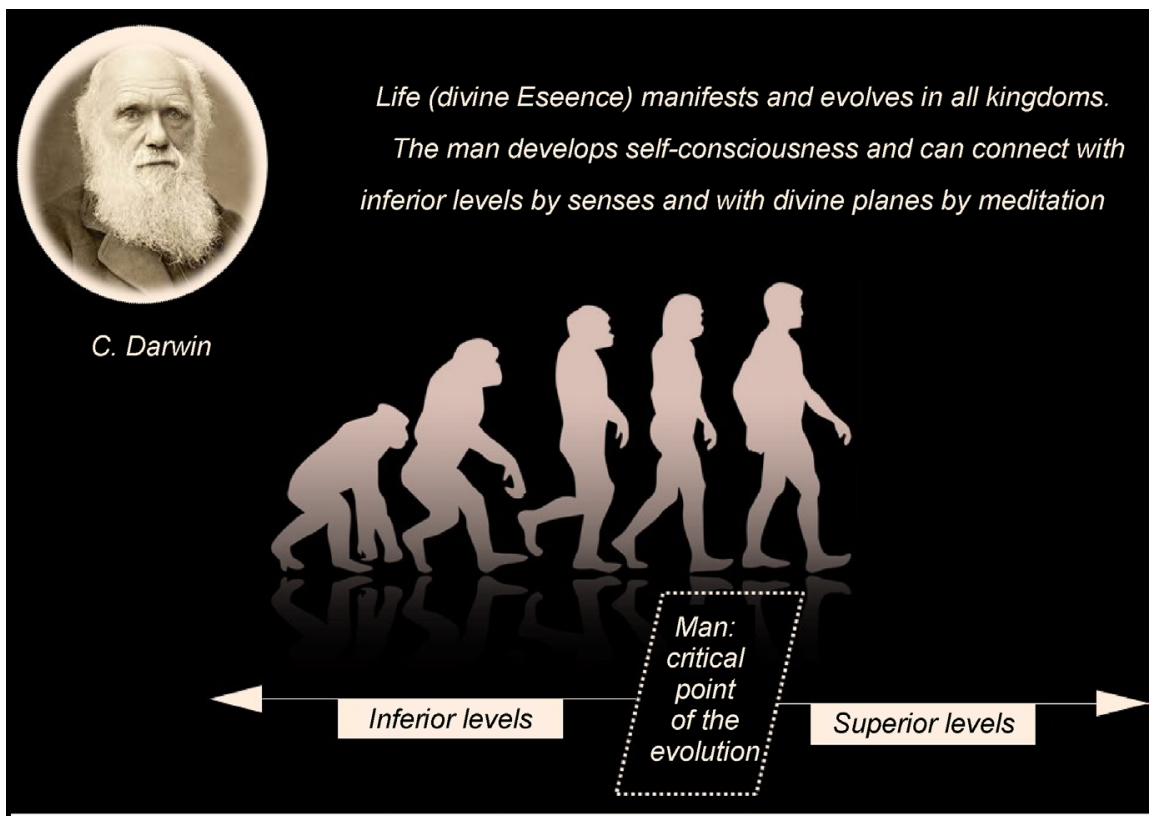

Figure 1. Life or divine essence, kingdoms and consciousness.

The Yogic experts indicate that the Yoga is reached by the meditation or Dhyana-as it is known in East-we must be interested, then in its real meaning. The word meditation comes from the Latin meditatio, which means contemplation; Dhyana is a Sanskrit term which is associated with subtle energy flow. Strictly speaking, the "Meditation is a State of higher spiritual-contemplative consciousness", in which mind is concentrated and engrossed in a divine idea. Note that this contemplation appears only when the "mental silence" free of physical and emotional sensations is reached. The Psychiatrist Michael McGee has defined meditation as a psychological state of active passivity and creative quiescence, in which the meditator purposefully and nonjudgmentally pays attention to present moment, attending to the multitude of sights, sounds, sensations, feelings, and thoughts that simultaneously present themselves to his or her awareness in each moment (McGee, 2008). The concept of meditation involves several ideas and that this process requires a personal work of introspection, perseverance and other noble virtues that are developed in the selfless disciple. All this leads to the threshold of the divine contact with the eternal spirit into the etheric camera of the heart. If you reader is interested, this superior consciousness state of meditation is taught by the spiritual practice known as "Raja Yoga", which is described by the spiritual Hindu Order, known as Suddha Dharma Mandalam (Janardana, 1946).

What contributions has the science done in relation to the fascinating topic of life and consciousness? In 1970 Dr. Stanley Miller (1930-2007), famous Biochemist from the University of California in the USA, realized interesting biopoiethic studies estimating (4 billion years ago) Earth's primitive atmosphere was reductive by volcanic vapors of inorganic gases of simple chemical structure including hydrogen, vapor water, methane, and ammonia. With this back- 
ground, Dr. Miller placed these 4 gases in a glass flask connected to electrodes with a spark (simulating a thunderstorm). This reaction allowed the formation of a liquid whose analysis revealed the presence of amino acids, basic units of the proteins and considered bricks of life (Miller, 1953; Miller \& Urey 1959a, 1959b). With this simple and ingenious experiment, Dr Miller showed that inorganic matter is transformed into more complex organic molecules reporting him the Nobel Prize. According to the science of Biochemistry, and so "life is synonymous of amino acid". Although Dr. Miller deserves all my respect and whom I had the honor of knowing in an international scientific conference in San Francisco the year 1991, I ask myself: is life just a bunch of amino acids? More recently, researchers at UCLA and the University of Wisconsin-Madison have confirmed that microscopic fossils discovered in a nearly 3.5 billion-year-old piece of rock in Western Australia are the oldest fossils ever found and indeed the earliest direct evidence of life on Earth (Schopf et al., 2018). Concerning to studies on conscience, current neuroscience research led by Dr. Philip Low from Harvard University, comes to 3 important conclusions: to a) all mammals and birds have a conscience; b) the brain areas responsible for emotions are similar; and c) animals and humans perceive and feel exactly the same stimuli. Currently humans maintain close communication and affective ties with different animals through adoption and family life with thousands of pets (dogs, cats, birds, etc.). Statistical data reveal that $70 \%$ of families in the actual world have $\operatorname{dog}(\mathrm{s})$ at home. An international group of prominent scientists has signed The Cambridge Declaration on Consciousness (Francis Crick Memorial Conference, July 7th, 2012) in which they are proclaiming their support for the idea that animals are conscious and aware to the degree that humans are-a list of animals that includes all mammals, birds, and even the octopus.

Yoga allows you to understand the purpose of life and live in a state of joy and openness. Through a scientific approach it invites their practitioners to search the Truth based on empirical data and search the transcendence of the senses, the mind and the intellect. The Yoga is only an instrument to guide in the road, but the applicant is the one who must walk it. Yoga leads man to understand his role in the universe, without being affected by any external stimuli and free from suffering, in a permanent state of Sat-Chit-Ananda (existence, knowledge and bliss). The Essence of the Being is beyond the physical, astral and causal bodies, which are considered as vehicles of the body. A Yogi must have full awareness that being is synonymous of Absolute and requires to reach self-realization to enter the State of freedom. To have knowledge of the Truth, the mind needs to be purified by the silence and the devotion. For East Yogis, human life results from a triple conjunction of Spirit (Atman), Matter (Prakriti) and Energy (Shakti) (Figure 2). According to teachings of the Brahmins, spirit and matter have no beginning and no end, by themselves or separate they are inert and inactive, but when Shakti join them, it appears the life. The spirit penetrates and vivifies the matter granting qualities, forms and movement. 


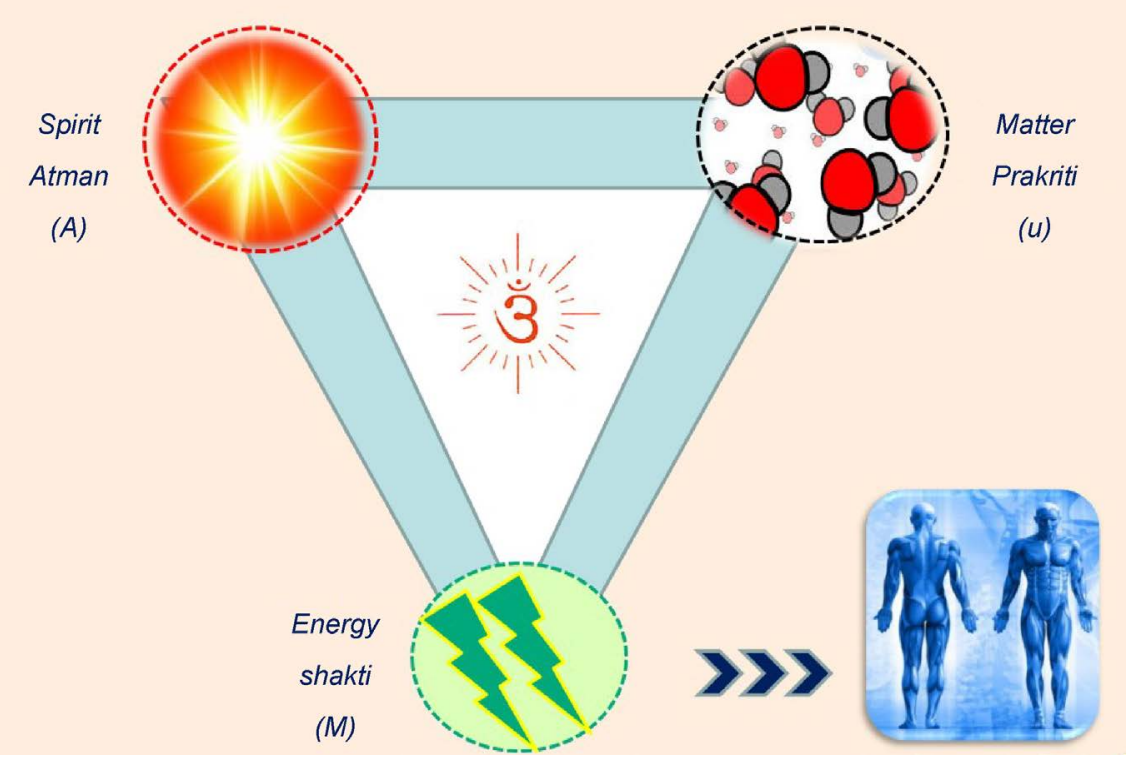

Figure 2. Manifestation of human beings.

\section{Is the human brain still evolving?}

The studies of neuroscience, based on triune brain, estimate that in the human brain resides the genealogical tree of the species as a result of the evolution of millions of years starting from the brain structure of the reptiles. The earliest part is the brain stem or reptilian brain that is connected to the spinal cord, which controls only the vegetative survival (food, reproduction, etc.). Then, primitive mammals overlapped the Limbic Brain with the hypothalamus that regulates the temperature and develop the emotional capacity (fear, pleasure, etc.). Later, the higher mammals add a new structure called neocortex or cerebral cortex where the cognitive faculties reside (learning, memory, will, etc.). The man has the most voluminous brain (around $1500 \mathrm{cc}$ ) reflecting further evolution and intelligence (!!). The neuroscientists say that modern man has developed only one-third of his mental capacity.

It is well-known that the triune brain was a model proposed by the American neuroscientist Paul MacLean around the year 1960 to explain the traces of evolution existing in the human brain. This model assumes the overlay in time (millions of years) of 3 structures including the reptilian brain, the limbic brain and neocortex associated with instincts, emotions and reasoning, respectively (MacLean, 1990; Smith, 2010). Although the theory of MacLean has been resisted by some current neurobiologists, if this postulate is valid, we could ask ourselves how the man brain will be within 1 or 10 million years. The evolution is a dynamic process that is adapted to the circumstances and the times. In this sense and for several decades, it seems to me that the discipline of Yoga is becoming strongly part in the psyche of the human world society as a system of healthy and spiritual life. Each day, millions of people access to different modalities of the Yoga modifying their habits and driving them by the trail of the Dharma 
(correct behavior). My hypothesis proposes development of second improved neocortex II with neuronal connections prevailing of noble human qualities, that I will baptize with the name of "intuitional brain", within the next millennia (Figure 3). This would allow the man to reach-among other-true peace, righteous, compassion-tolerance and unity. Neurological studies reveal that network design of interconnected neurons vary with selfish and non-selfish thoughts. Recently Dr Richard Davidson, a well-known and famous psychiatrist who also practices meditation techniques, has demonstrated that network neurons of human depression are completely different from those in tenderness. He concludes that "goodness is the base of a healthy brain" (Davidson, 2000, 2004, 2012).

\section{Suddha Dharma Mandalam}

The Suddha Dharma Mandalam (SDM) is a sacred Spiritual Order whose Sanscrit term is translated in the following way: Suddha = eternal or pure, Dharma $=$ straight lifestyle, and Mandalam $=$ organization. However, SDM is also the name of an ancient divine hierarchy that directs the evolution of all beings, which is composed of a Director (Narayana) and a whole host of spiritual beings. This discipline has solid philosophical knowledge, various spiritual practices and initiations granted by Divine Teachers of the Mandalam. This sacred spiritual science was initially communicated to the world in the India of 1915 by two eminent wise and External Initiatories, Swami Dr Subramania Iyer and Pandit Srinivasachariar. Then, this yogic doctrine reached Sri Vayera Yogi Dasa in Chile who spread it to the whole West leaving a Spiritual legacy which is reflected today in schools and Ashrams distributed in America and Europe. SDM is the pre-eminent philosophical system that contains the most vital principles about life and conduct, aimed at the achievement of the material and spiritual

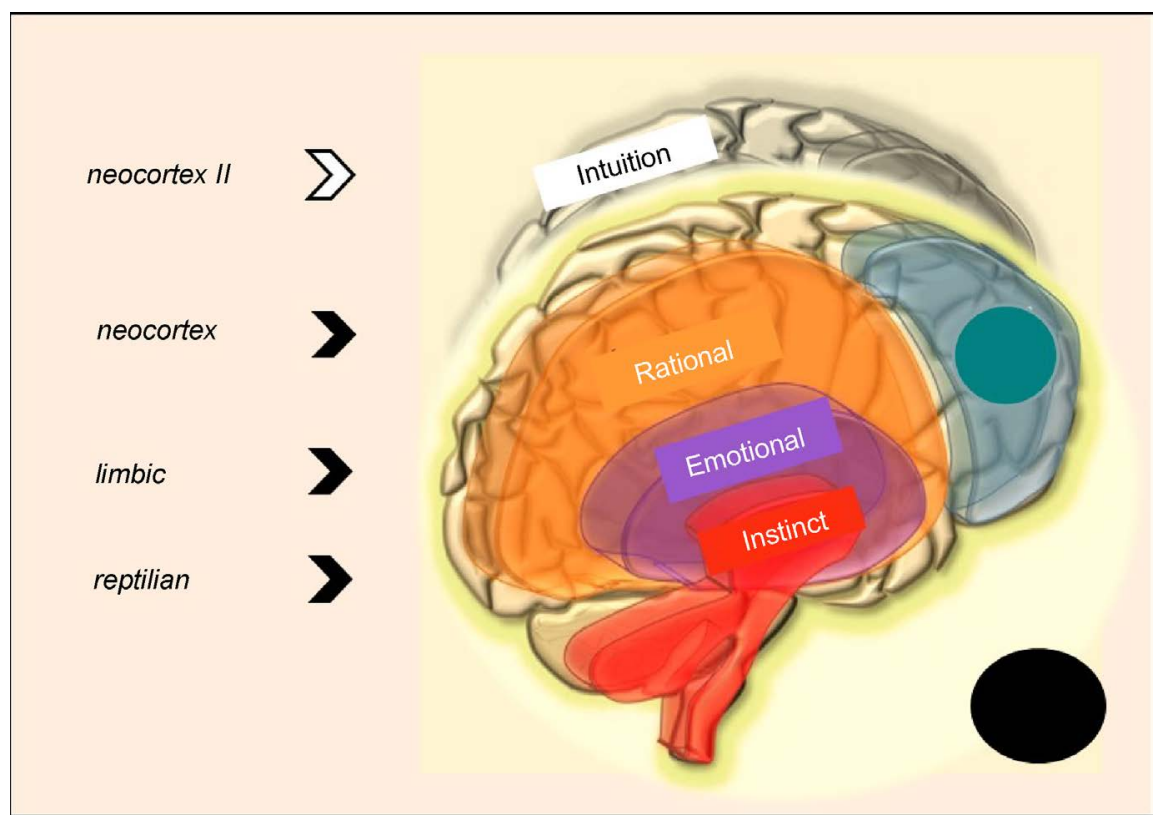

Figure 3. Hypothesis on intuitional brain. 
progress of humanity. The main objectives include a) to study the nature of man and the universe; b) to study its relative position in the universe; $c$ ) to coordinate the life inside and outside; and d) to perform through Yoga the Divinity present in the subtle heart (Janardana, 1951). Among many others, this Spiritual Mystic Yoga Order recommends to their disciples cultivate the noble Atmic qualities including goodness, welfare and purity (Hamsa, 1917). Based on this information, I propose a possible correlation between human nobility and neuronal network for a healthy brain (Figure 4).

The Yoga has been recognized today as an intangible heritage of the humanity by the Unesco since it shakes conscience allowing to live in harmony with the environment and respecting all the beings manifested in this planet known as Earth. This idealistic speculation is perhaps laughable or utopian to many people, but the world should be different if the human beings related to others from the Soul and not from the Ego. Some spiritualists believe that, if we teach Yoga to children, we would eliminate violence in a single generation. Today, Yoga for children is a reality in many countries and the demand continues to grow as a social imperative need to combat stress, separateness, anxiety, competition, insecurity, etc. Making an analogy with an algebraic trinomial $(x+y+z)$ we could say that-if life is learning ( $\mathrm{x}$ - - if life is growth (y) and if life is evolution (z), then Life is Yoga, integral knowledge of a man (himself) ranging from transient dense appearance to eternal subtle spirit.

\section{Conclusion}

The classical well-known triune brain proposed by Paul MacLean in 60s, estimates that in the human brain resides the genealogical tree of the species as a result of the evolution of millions of years starting from the brain structure of the reptiles. Like biological evolution, it is also possible to consider a spiritual evolution through also different kingdoms of nature. A human being is not only

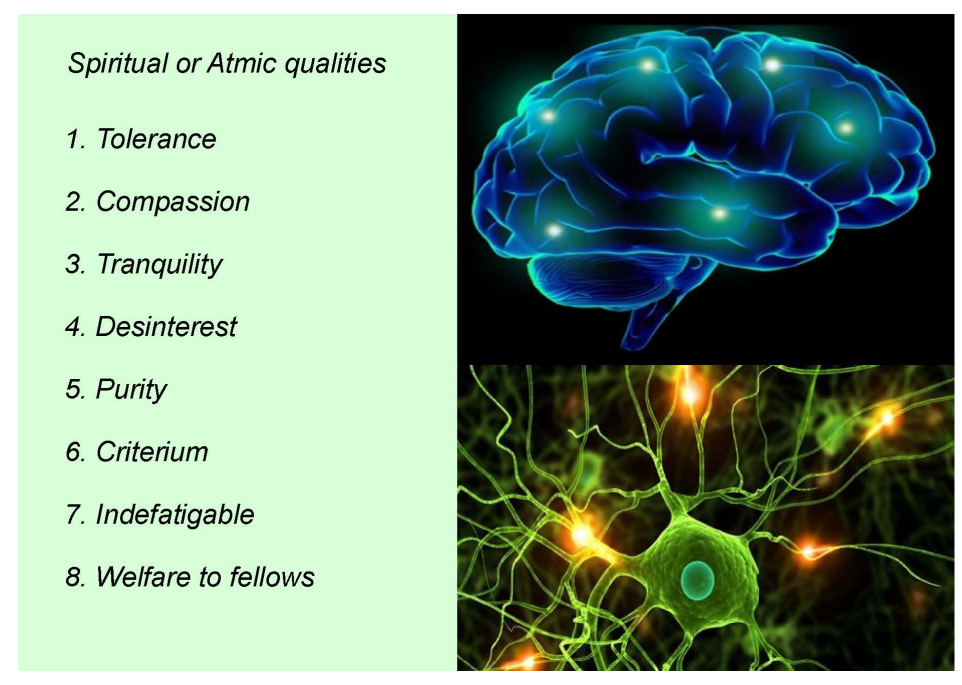

Figure 4. Correlation between human nobility and healthy brain. 
Homo sapiens (transitory physical body), but also Homo moralis (transitory inferior conscience) and Homo spiritualis (eternal Superior Conscience). This study postulates in next millennia the development of improved neocortex II or "intuitional brain" with neural networks prevailing human noble qualities and subtle essential unity among beings.

While for scientists the "experimental laboratory-tool" is the way to demonstrate the transitory material existence, for the yogis the "experimental meditation-tool" is the way to demonstrate the perennial divine existence. According to Vedic teachings, the mind might move through 5 different planes: from sense organs, to emotions, to thoughts, to intellect perceptions and to wisdom intuitions. While the 3 first planes dealing with lower individual material personality, the other 2 planes dealing with superior divine spirit unity. Most of human beings work by using a communication system through lower faculties including neuro-sensory for sense organs, bio-energy for feelings and reason for thoughts. However, there are some gifted people who raise their consciousness to superior levels through intuition for immediate learning and wisdom attaining direct perception of Divine Truth.

When a human being elevates the mind to higher planes, he promotes the virtuous qualities of man. Experts from different areas including philosophers and biologists propose that if we teach Yoga to children, the world violence would be eliminated in a single generation.

\section{Acknowledgements}

C.M. thanks to Dr Jean-Marc Cavaillon from Institute Pasteur, Paris-France for the scientific knowledge and to his venerable spiritual Master "Vayera Yogi Dasa" for the Suddha teachings.

\section{Conflicts of Interest}

The author declares no conflicts of interest regarding the publication of this paper.

\section{References}

Ayala, F. J. (1986). Whither Mankind? The Choice between a Genetic Twilight and a Moral Twilight. American Zoologist, 26, 895. https://doi.org/10.1093/icb/26.3.895

Bagchee, J., \& Adluri, V. (2016). Who's Zoomin' Who? Bhagavadgita Recensions in India and Germany. International Journal of Dharma Studies, 4, 1-41. https://doi.org/10.1186/s40613-016-0026-8

Cela-Conde, C. J., \& Ayala, F. J. (2007). Human Evolution. Trails from the Past. Oxford: Oxford University Press.

Davidson, R. J. (2000). Anxiety, Depression, and Emotion. New York: Oxford University Press. https://doi.org/10.1093/acprof:oso/9780195133585.001.0001

Davidson, R. J. (2004). Well-Being and Affective Style: Neural Substrates and Biobehavioural Correlates. Philosophical Transactions of the Royal Society B: Biological Science, 359, 1395. https://doi.org/10.1098/rstb.2004.1510 
Davidson, R. J. (2012). The Emotional Life of Your Brain: How Its Unique Patterns Affect the Way You Think, Feel, and Live and How You Can Change Them. London: Penguin Books.

Hamsa, Y. (1917). Sanatana Dharma Deepika, or Anushthana Chandrika. Suddha Dharma Mandalam (Vol. 1). Sreenivasachariar, Modern Printing Works, Mount Road, Madras, India.

Higham, T. et al. (2014). The Timing and Spatiotemporal Patterning of Neanderthal Disappearance. Nature, 512, 306.

Janardana, T. M. (1946). Suddha Raja Yoga of Sri Hamsa Yogi (Text with English Translation). Mylapore, Madras, India: The Suddha Dharma Office.

Janardana, T. M. (1951). Suddha Dharma Mandalam, the Divine Hierarchy, Its Scope and Purpose. Mylapore, Madras, India: The Suddha Dharma Office.

Lander, E. S. et al. (2001). International Human Genoma Sequencing Consortium Initial Sequencing and Analysis of the Human Genome. Nature, 409, 860-921. https://doi.org/10.1038/35057062

MacLean, P. D. (1990). The Triune Brain in Evolution. Role in Paleocerebral Functions. New York: Plenum.

McGee, M. (2008). Meditation and Psychiatry. Psychiatry, 5, 28.

Miller, S. L. (1953). A Production of Amino Acids under Possible Primitive Earth Conditions. Science, 3046, 528. https://doi.org/10.1126/science.117.3046.528

Miller, S. L., \& Urey, H. C. (1959a). Origin of Life. Science, 130, 1622. https://doi.org/10.1126/science.130.3389.1622-a

Miller, S. L., \& Urey, H. C. (1959b). Organic Compound Synthesis on the Primitive Earth. Science, 130, 245. https://doi.org/10.1126/science.130.3370.245

Munoz, C. et al. (2020) Suddha Dharma Mandalam Bhagavad Geeta. The Aryan Philosophy Current Today. Open J Philos, 10, 220.

Reigle, D. (2007). Publications of the Suddha Dharma Mandala (pp. 1-17). Cotopaxi, CO: Eastern Tradition Research Institute.

Richerson, P. J. et al. (2005). Not by Genes Alone. Chicago, IL: University of Chicago Press.

Schopf, J. W. et al. (2018). Oldest Fossils Ever Found Show Life on Earth Began before 3.5 Billion Years Ago. Proceedings of the National Academy of Sciences of USA, 115, 53.

Sequencing, T. C. et al. (2005). Chimpanzee Sequencing and Analysis Consortium. Initial Sequence of the Chimpanzee Genome Comparison with the Human Genome. Nature, 437, 69. https://doi.org/10.1038/nature04072

Smith, C. U. (2010). The Triune Brain in Antiquity: Plato, Aristotle, Erasistratus. Journal of the History of the Neurosciences, 19, 1-14. https://doi.org/10.1080/09647040802601605

Varki, A., Geschwind, D. H., \& Eichler, E. E. (2008). Explaining Human Uniqueness: Genome Interactions with Environment, Behaviour and Culture. Nature Reviews Genetics, 9, 749. https://doi.org/10.1038/nrg2428

Woodhouse, M. B. (1978). Consciousness and Brahman-Atman. The Monist, 61, 109. https://doi.org/10.5840/monist19786115 